\title{
Article \\ Manufacturing Optically Transparent Thick Zirconia Ceramics by Spark Plasma Sintering with the Use of Collector Pressing
}

\author{
Vladimir Paygin ${ }^{1, *} \mathbb{\infty}$, Edgar Dvilis ${ }^{1}$, Sergey Stepanov ${ }^{1} \oplus$, Oleg Khasanov ${ }^{1}$, Damir Valiev ${ }^{1}$, Timofei Alishin ${ }^{1}$,

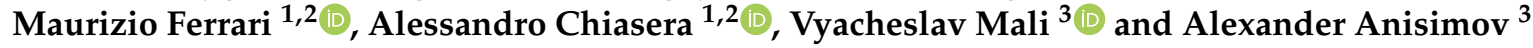 \\ 1 Innovation Center for Nanomaterials and Nanotechnologies, School of Advanced Manufacturing \\ Technologies, National Research Tomsk Polytechnic University, Lenin Avenue 30, 634050 Tomsk, Russia; \\ dvilis@tpu.ru (E.D.); stepanovsa@tpu.ru (S.S.); khasanov@tpu.ru (O.K.); rubinfc@tpu.ru (D.V.); \\ tra1@tpu.ru (T.A.); maurizio.ferrari@ifn.cnr.it (M.F.); alessandro.chiasera@ifn.cnr.it (A.C.) \\ 2 Institute for Photonics and Nanotechnologies (CNR), Via allaCascata, 56/C, Povo, 38123 Trento, Italy \\ 3 Lavrentyev Institute of Hydrodynamics SB RAS, pr. ac. Lavrentyeva 15, 630090 Novosibirsk, Russia; \\ vmali@mail.ru (V.M.); anis@hydro.nsc.ru (A.A.) \\ * Correspondence: vpaygin@mail.ru; Tel.: +7-3822-606-164 (ext. 5248)
}

Citation: Paygin, V.; Dvilis, E.; Stepanov, S.; Khasanov, O.; Valiev, D.; Alishin, T.; Ferrari, M.; Chiasera, A.; Mali, V.; Anisimov, A. Manufacturing Optically Transparent Thick Zirconia Ceramics by Spark Plasma Sintering with the Use of Collector Pressing. Appl. Sci. 2021, 11, 1304. https:// doi.org/10.3390/app11031304

Academic Editor: Yuzo Nakamura Received: 11 December 2020

Accepted: 26 January 2021

Published: 1 February 2021

Publisher's Note: MDPI stays neutral with regard to jurisdictional claims in published maps and institutional affiliations.

Copyright: (c) 2021 by the authors. Licensee MDPI, Basel, Switzerland. This article is an open access article distributed under the terms and conditions of the Creative Commons Attribution (CC BY) license (https:// creativecommons.org/licenses/by/ $4.0 /)$.

\begin{abstract}
The efficiency of using the collector pressing scheme in the Spark Plasma Sintering (SPS) process has been confirmed in improving the optical, physical, and mechanical properties of yttriastabilized zirconia (YSZ) ceramics with an increased shape factor. An approach for developing a seal surface and determining the optimal method of increasing pressure and temperature during SPS on this surface was used to optimize the consolidation modes of the materials. It has been shown that transparent/translucent YSZ ceramics with an increased shape factor (14 $\mathrm{mm}$ in diameter and up to $5 \mathrm{~mm}$ in height, $\mathrm{h} / \mathrm{d}=0.36$ ) can be successfully fabricated by the SPS technique combined with the collector pressing scheme. The optical properties and microhardness of ceramics obtained using the collector scheme are better to the optical properties of ceramics obtained using the conventional uniaxial pressing scheme.
\end{abstract}

Keywords: collector pressing; Spark Plasma Sintering; yttrium-stabilized zirconia; transparent ceramics

\section{Introduction}

Spark Plasma Sintering (SPS) is a widespread and promising technique for consolidation of nanostructured materials. It is widely used for nanostructured materials fabrication such as optical ceramics, composites, and functionally gradient materials for applications in various fields [1].

The SPS technique combines simultaneous compression and thermal action on the material. Unlike hot pressing techniques, SPS heating is accomplished by passing a direct current pulse train through the die and sintered material. Typically, dies are made of graphite, the tensile strength of which is limited to $120 \mathrm{MPa}$, and the maximum prepressing pressure is limited by this value. The use of high current values for the SPS process can significantly reduce the temperature and decrease the sintering time. The technique provides the preservation of the initial phase composition, submicron structure, and a high density of consolidated polycrystalline materials, which is close or equal to the theoretical one $[2,3]$.

Controlling of various parameters during the SPS process (e.g., pulse relative duration, heating and cooling rate, holding time, temperature, pressure) in a wide range allows fabrication of the various materials with controlled properties, from nano- to sub-micropowders, and optimization the sintering process according to various criteria [4].

One of the main problems of the SPS technique is the limitation of usage of a high pressures above $120 \mathrm{MPa}$. In recent decades, various scientific groups focus on solving this drawback. Guillon et al. have practically expanded the range of working pressures of 
prepressing, lowering the sintering temperature range. For this purpose, the dies made of hard alloys, molybdenum composite (TZM), tungsten carbide (WC-Co) or silicon carbide (SiC) were applied [5]. Anselmi-Tamburini and colleagues have developed a double die [6]. The elements of the die are composed of graphite and SiC or WC. It allows the use of pressures up to $1 \mathrm{GPa}$ without lowering the sintering temperature [7]. Various groups have reported the application of ultra-high-pressures during the SPS process (up to $10 \mathrm{GPa}$ ) and sintering temperatures of up to $1950^{\circ} \mathrm{C}$ by combining a pulse electric power source with Toroid (Bridgman) type or Belt type with special die construction $[1,4,8,9]$.

Another, no less important, problem of the SPS technique which has received less attention in the literature is the fabrication of materials with complex shapes. The solution to this problem is the approach of combining the SPS with alternative compaction techniques for powder materials. Barinov et al. have demonstrated a solution to this problem by combining SPS and a quasi-static pressing method [10]. They successfully fabricated a hemispherical titanium product with a porous outer coating.

In our opinion, the use of deformation schemes with a redistribution of friction forces during pressing of dry powders in the SPS method seems to be a promising solution to overcome this problem. It makes it possible to improve the quality of consolidated materials and expand the range of products. In particular, it is promising to use the collector pressing scheme [11]. The principle of the technique is to form multidirectional forces of wall friction, which provides a constant value of pressing pressure, which is transmitted without loss to all layers of the powder body along the pressing axis. This provides the same degree of compaction of the layers, minimizes the density and stress gradients in the volume of the pressed materials, and significantly reduces the likelihood of macrodefects in the sintered product. Another advantage of the method is the ability to expand the allowable range of pressing pressures beyond the strength of the die material.

In this work, the SPS technique in combination of the collector pressing method is used to produce transparent ceramics based on yttrium-stabilized zirconia (YSZ) with an increased shape factor. The study of the influence of the pressing method on the elastoplastic and optical properties of YSZ ceramics has been carried out.

\section{Materials and Methods}

YSZ ceramics were prepared from commercial cubic yttrium-stabilized zirconia nanopowder (TZ-10YS, TOSOH corp., Shunan, Japan). The SPS-515S installations (Syntex Inc., Kawasaki, Japan) at Tomsk Polytechnic University and Labox 1575 (Sinter Land Inc., Kawasaki Japan) at the Lavrentyev Institute of Hydrodynamics SB RAS were used for powder consolidation. The sintering process was carried out in a vacuum $\left(10^{-3} \mathrm{~Pa}\right)$ at a temperature of $1300{ }^{\circ} \mathrm{C}$. Heating from room temperature to $1000{ }^{\circ} \mathrm{C}$ was carried out at a rate of $15^{\circ} \mathrm{C} / \mathrm{min}$-from 1000 to $1300{ }^{\circ} \mathrm{C}$ at the rate $10{ }^{\circ} \mathrm{C} / \mathrm{min}$. The holding time at a given sintering temperature was $10 \mathrm{~min}$. The pulse relative duration was 3:1. The temperature during sintering was controlled by a high-temperature pyrometer through a technological hole made on the side surface of the graphite die. Pressing in the SPS process was conducted using both the conventional uniaxial method and collector pressing. The prepressing pressure throughout the SPS process remained unchanged and amounted to $100 \mathrm{MPa}$. A detailed description of the selected sintering mode is presented in [12].

The collector pressing method was implemented by using split dies of various designs. The dies consisted of two solid or composite forming elements moving oppositely during the pressing process. They contained part of the active and part of the passive forming surfaces. The powder compaction occurred due to their mutual counter-movements when sliding along each other along the pressing axis [11]. Figure 1 shows a die with counter-moving parts of the passive forming surface (elements 4 and $4^{\prime}$ ), designed by us to implement the collector pressing scheme in the SPS process. 


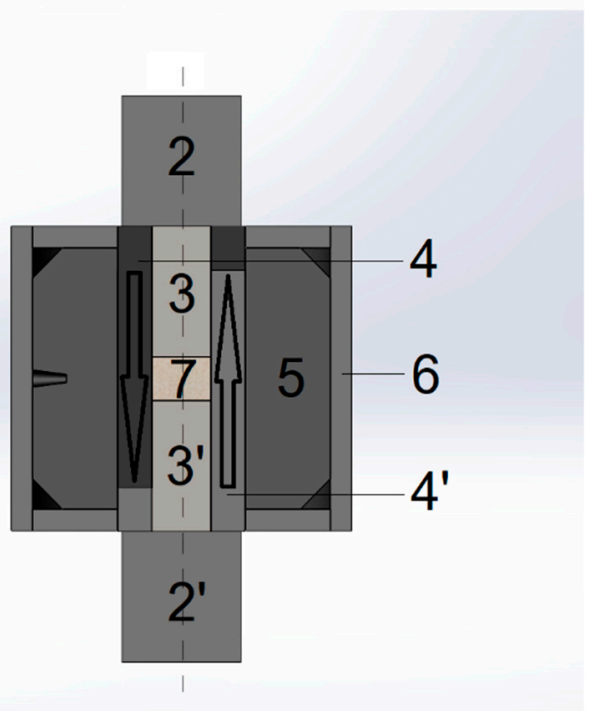

(a)

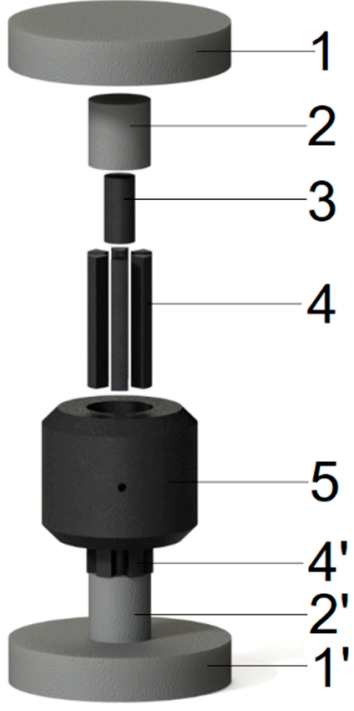

(b)

Figure 1. Schematic representation (a); the appearance of the collector mold: 1, 1', 2, 2' — graphite spacers; 3 and 3'-punches; 4 and 4 ' - constituent parts of the forming elements; 5-matrix; 6-graphite insulation; 7-powder. (b) The arrows indicate the direction of movement of forming elements.

In order to gain statistically reliable data, 3 samples of each thickness were obtained for both pressing methods. Transparent cylindrical ceramic specimens with diameters of $14 \mathrm{~mm}$ and heights of 2.5 to $5.5 \mathrm{~mm}$ were obtained by the SPS technique. Further study of the ceramics was carried out after mechanical polishing of their end surfaces on an EcoMet 300 Pro grinding and polishing system (Buehler, Germany) using Kemix diamond suspensions (Kemika, Russia). The height $(h)$ of the polished samples ranged from 2 to $5 \mathrm{~mm}$, which corresponds to a shape factor (ratio of height to diameter) of 0.14 to 0.36 .

The YSZ ceramics were annealed in an atmospheric furnace LHT 02/18 (Nabertherm, Germany) in an air atmosphere at $800{ }^{\circ} \mathrm{C}$ for $4 \mathrm{~h}$ to achieve optimal stoichiometry with respect to oxygen and to reduce the concentration of defects associated with oxygen vacancies formed in the SPS process in a vacuum.

The study of the rheological characteristics of the powder body consolidated by the SPS technique was carried out using the method of approximating the experimental compaction data by a dimensionless equation of a logarithmic form [13]:

$$
\rho=b \cdot \ln \left(\frac{P_{p}}{P_{c}}+\left[\frac{T_{p}}{T_{c}}\right]^{n}\right)+1
$$

where $\rho$ is the relative density of the powder body, $b$ is the coefficient characterizing the intensity of compaction of the powder body under the action of the pressing pressure, $P_{p}$ is the pressing pressure, $P_{c}$ is the critical pressing pressure at which the nonporous state of the powder body is achieved, $T_{p} / T_{c}$ is the relative temperature, and $n$ is the power constant, which characterizes the rate of change of the relative density with increasing temperature.

$X$-ray phase analysis of the initial YSZ powder and ceramics was characterized using an XRD-7000S X-ray diffractometer (Shimdazu, Japan) using $\mathrm{Cu} K_{\alpha}$ radiation $(\lambda=1.54,056 \AA$ ). The interpretation of the results was conducted using the PDF- 4 international crystallographic database and PowderCell 2.4 free software.

The study of the optical properties of ceramic samples was measured in the ultraviolet, visible, and near-infrared regions of the spectrum using an SF-256 UVI double-beam scanning spectrophotometer (190-1100 nm) (Lomo-Photonics, Russia). The diffuse transmittance measurement accuracy was $\pm 0.1 \%$. The transmission coefficients were measured 10 times for each sample and the deviation from mean did not exceed $1 \%$. 
The study of the elastoplastic properties and Vickers microhardness $\left(\mathrm{H}_{\mathrm{V}}\right)$ of YSZ ceramics was analyzed by the method of indentation with a diamond pyramid according to the standard technique on a DUH-211S ultramicrohardness tester (Shimadzu, Japan) at a load of $1.96 \mathrm{~N}$ [14].

\section{Results}

The results of studying the rheological properties of YSZ powder during the SPS process with various pressing schemes are presented in Table 1. Spark Plasma Sintering of YSZ ceramics is satisfactorily described by Equation (1). The use of a collector pressing scheme in the SPS process can significantly increase the intensity of compaction of the test material (coefficient $\mathrm{b}$ ). It allows decreasing the critical pressing pressure $P_{c}$ by half and reducing the critical temperature $T_{c}$ of material flow by more than one hundred degrees Celsius.

Table 1. Rheological characteristics of the sintered ceramics under Spark Plasma Sintering (SPS) conditions.

\begin{tabular}{ccccc}
\hline Pressing Scheme & $\boldsymbol{b}$ & $\boldsymbol{P}_{\boldsymbol{c}}, \mathbf{M P a}$ & $\boldsymbol{n}$ & $\boldsymbol{T}_{\boldsymbol{c}},{ }^{\circ} \mathbf{C}$ \\
\hline Uniaxial pressing & 0.0280 & 11.687 & 59.30 & 1498 \\
Collector pressing & 0.0444 & 5128 & 54.14 & 1378 \\
\hline
\end{tabular}

The graphical representation of the seal surface (Figure 2) described by Equation (1) makes it possible to assess the possibilities of achieving a nonporous state of the consolidated material and to optimize the SPS sintering modes by combining increasing pressure and temperature. The optimal line is the most intense gradient descent from an arbitrary point lying on the top of the seal surface.

a
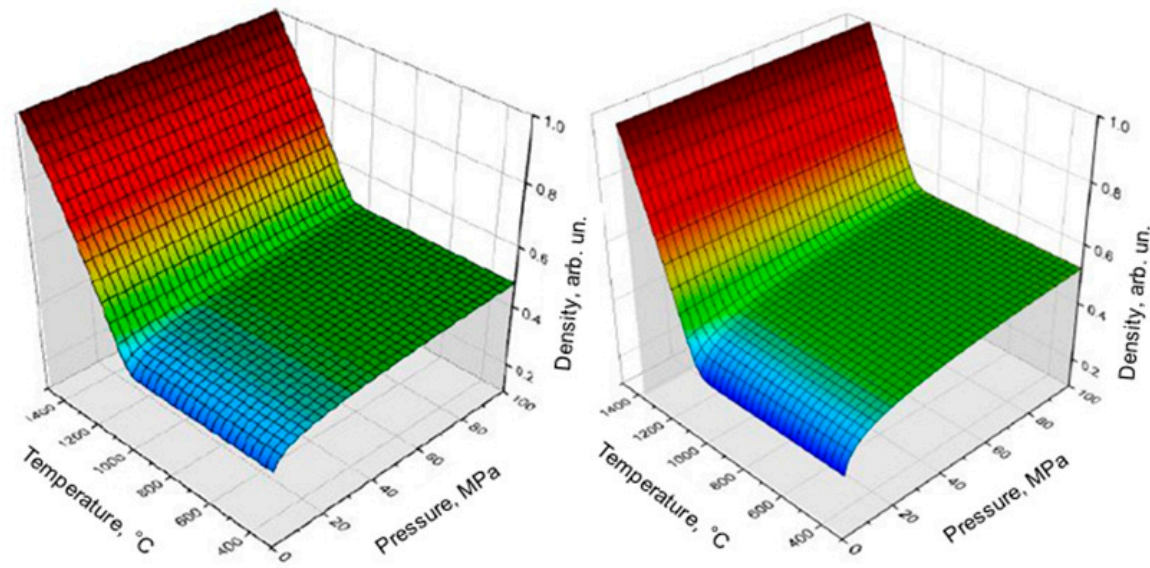

b

Figure 2. Compaction surfaces of yttrium-stabilized zirconia (YSZ) powder during consolidation by the SPS technique using various pressing schemes: (a) uniaxial pressing and (b) collector pressing.

The development of a line for the transcendental surface, Equation (1), presents a certain problem. Nevertheless, numerical methods make it possible to develop this line with an accuracy sufficient for practical applications. The algorithm for the line developing at the most intense descent on the seal surface takes into account the direction of the local gradient using the normal isoline (dashed line in Figure 3a) and the density isoline at a given point, Equation (1). The intersection point of this normal isoline with the next density isoline was selected with an extremely small step from the previous isoline. The sequential execution of these actions allows the curve (path) of the most intense gradient descent (red circles in Figure $3 b$ ) to be drawn on the seal surface as a set of intersection points of normal isolines to the density isoline with the next density isoline. 

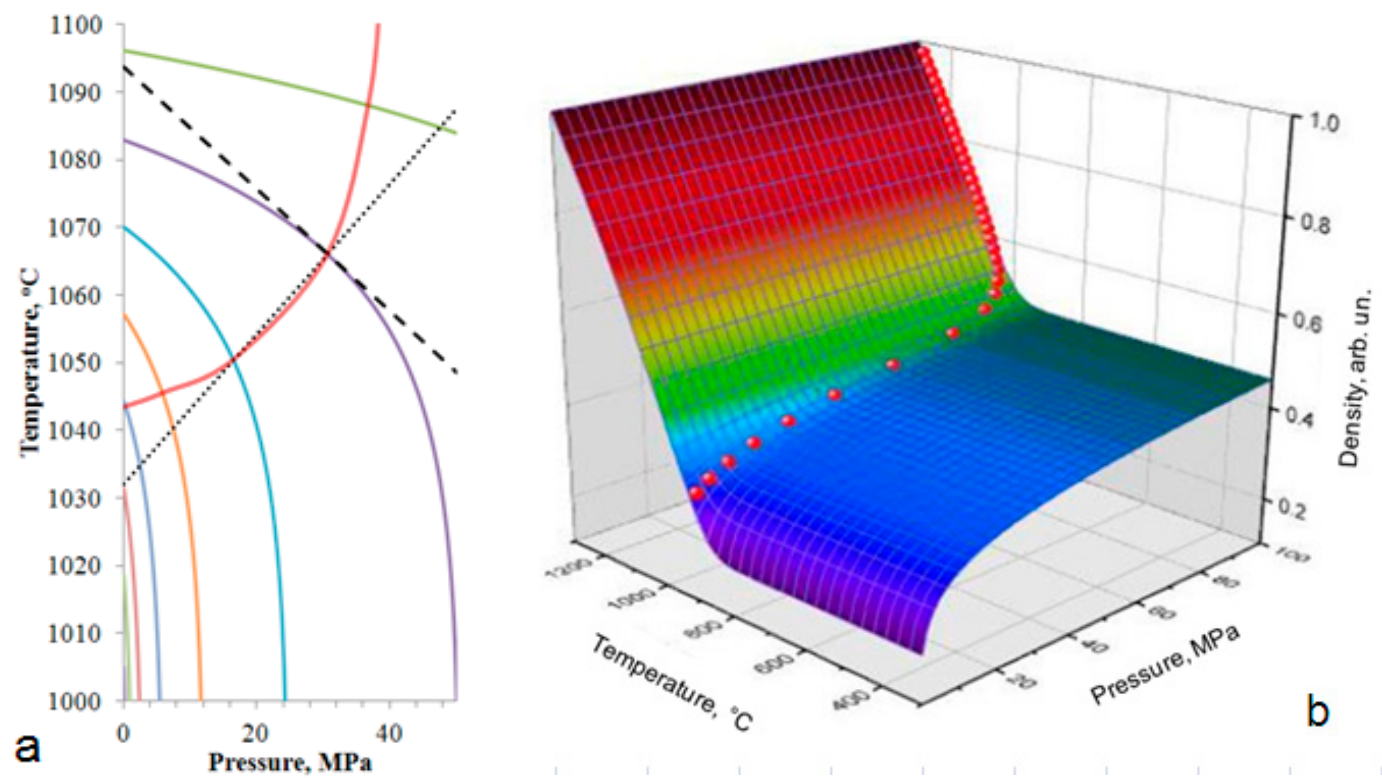

Figure 3. Graphical representation of the algorithm for developing the line of the most intense gradient descent (a-red line) and an example of the seal surface at SPS process with this line; (b-noted by red markers).

The results of the study of the rheological properties of the YSZ powder quantitatively confirm that the combination of SPS with rational methods of deformation is promising for the fabrication of transparent YSZ ceramics. The proposed technique for developing the line of the most intense gradient descent on the surface (1) can be effectively used to optimize the SPS consolidation of ceramics.

X-ray phase analysis (Figure 4) showed that the YSZ ceramics consisted of cubic zirconium dioxide with a lattice parameter $a$ in the range from 5.144 to $5.146 \AA$. The sizes of the coherent scattering regions (CSRs) of the cubic phase (crystallite sizes $D$ ) and their relative microstresses $\epsilon$ were determined from the broadening of the reflections in the diffraction pattern. The parameters of the crystal structure are the weighted profile R-factor (Rwp) characterized the reliability of microstructure parameters by the Rietveld method [15] and microhardness of YSZ ceramics (see Table 2).

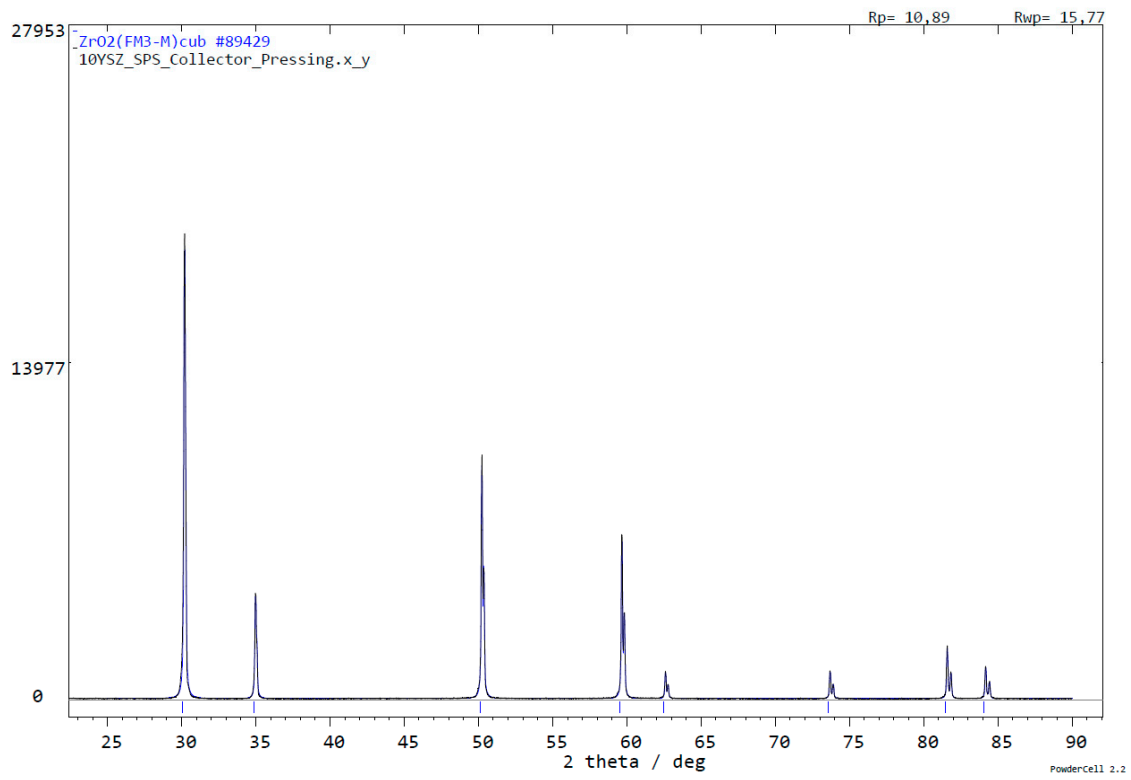

Figure 4. Typical XRD patterns of YSZ ceramics sintered by SPS at $1300{ }^{\circ} \mathrm{C}$. 
Table 2. Parameters of the crystal structure and microhardness of YSZ ceramics.

\begin{tabular}{ccccccc}
\hline Pressing Scheme & $\mathbf{h}, \mathbf{~ m m}$ & $\mathbf{H V}, \mathbf{G P a}$ & $\mathbf{a}, \mathbf{A}$ & $\mathbf{D}, \mathbf{n m}$ & $\mathbf{\varepsilon}, \mathbf{a r b}$. unit & Rwp, \% \\
\hline \multirow{4}{*}{ Uniaxial pressing } & 2 & $15.3 \pm 0.4$ & 5.146 & 587 & 0.000075 & 15.77 \\
& 3 & $14.2 \pm 0.1$ & 5.146 & 610 & 0.000116 & 15.91 \\
& 4 & $14.9 \pm 0.6$ & 5.144 & 748 & 0.000083 & 16.06 \\
Collector pressing & 5 & $15.5 \pm 0.3$ & 5.145 & 431 & 0.000141 & 15.88 \\
\hline & 2 & $16.4 \pm 0.9$ & 5.145 & 433 & 0.000082 & 15.84 \\
& 4 & $15.6 \pm 0.6$ & 5.145 & 337 & 0.000071 & 15.83 \\
& 5 & $15.6 \pm 0.9$ & 5.145 & 507 & 0.000059 & 15.74 \\
\end{tabular}

The Vickers microhardness of ceramics, with an increase in height from 2 to $5 \mathrm{~mm}$, changed nonmonotonically within the range of values from $14.2 \pm 0.1$ to $15.5 \pm 0.3 \mathrm{GPa}$ for specimens made using uniaxial pressing, respectively. For YSZ ceramics sintered using collector pressing, the $H_{V}$ parameter lies in the range from 16.4 to $16.2 \mathrm{GPa}$ and does not go beyond the confidence interval for measuring this value.

Based on XRD results, the YSZ ceramics fabricated using the collector pressing scheme are characterized by an average level of relative microstresses of the crystal lattice of 0.000069 and average crystallite size of $468 \mathrm{~nm}$. The ceramics prepared using the uniaxial pressing scheme are characterized by an average level of relative microstresses of the crystal lattice of 0.000104 and large crystallite sizes of $594 \mathrm{~nm}$.

Figure 5 shows the transmission spectra of YSZ ceramics and the transmission value at a wavelength of $\lambda=600 \mathrm{~nm}$, fabricated using collector and uniaxial pressing schemes in the SPS process.
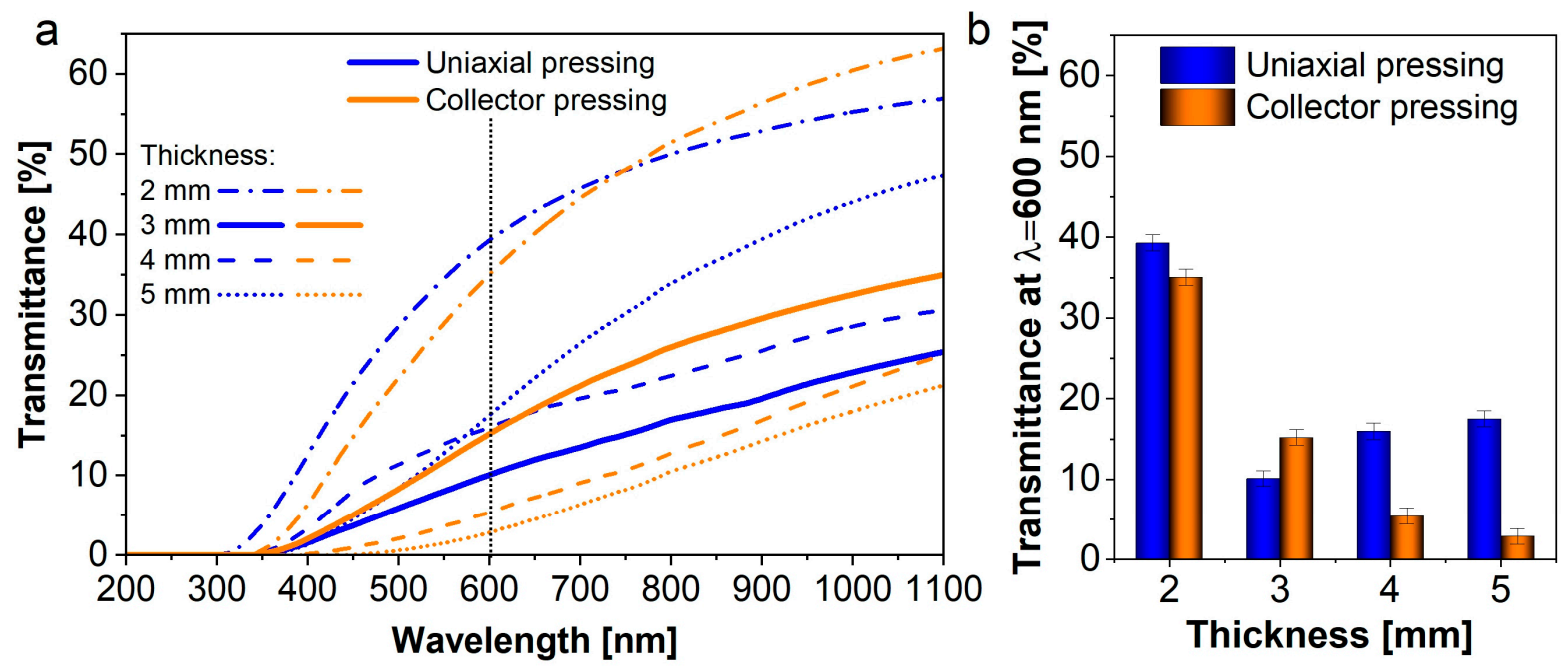

Figure 5. Diffuse transmission spectra (a) and transmission coefficient value at $\lambda=600 \mathrm{~nm}(\mathbf{b})$ of YSZ ceramics.

YSZ sintered ceramics with various heights demonstrate high levels of transparency in a wide spectral range. The transmission level reached $12.4 \%$ in the ultraviolet, $45.8 \%$ in the visible, and $59.9 \%$ in the infrared spectral regions, respectively. The transmittance edge is located in the spectral region of $350 \mathrm{~nm}$ and does not depend on the consolidation conditions. It can be determined by the ceramic thickness.

With an increase in the height of YSZ ceramic specimens fabricated by uniaxial pressing in the SPS process, from 2 to $3 \mathrm{~mm}$, a decrease in light transmission from $39.3 \%$ to $10.1 \%$ was observed. With a further increase in sample height from 3 to $5 \mathrm{~mm}$, an anomalous increase in light transmission was observed from $10.1 \%$ to $17.5 \%$. For samples sintered using collector pressing in the SPS process, with an increase in height from 2 to $5 \mathrm{~mm}$, a 
decrease in light transmission from $35.1 \%$ to $2.9 \%$ was observed. The highest value was achieved at a ceramic thickness of $2 \mathrm{~mm}$.

\section{Discussion}

Free oxygen vacancies are formed in YSZ ceramics during the SPS process, because of thermal action in a reducing environment [16]. The formed vacancies are centers of light scattering and have a negative effect on the optical properties. Thermal annealing of YSZ ceramics in an oxygen-containing atmosphere makes it possible to restore the oxygen stoichiometry and improve the optical properties [17-19].

The high transparency values for the YSZ ceramics obtained in the present work are apparently related to the duration of the saturation process and the number of oxygen vacancies not recovered during heat treatment in the air. In our opinion, to increase the light transmission of high/bulky ( $>3 \mathrm{~mm}$ thick) ceramics with an increased shape factor, it is necessary to increase the saturation time of oxygen vacancies by increasing isothermal holding at a given annealing temperature or to significantly reduce the rate of temperature change to $10-50{ }^{\circ} \mathrm{C} / \mathrm{h}$.

The presented approaches to optimizing the SPS modes for YSZ sintering ceramics may raise some doubts related to the accuracy of temperature control for the sintered ceramics. The radiation pyrometer, which recorded temperatures on the outside of the die, is typically used during the SPS process. The quantitative distributions of temperature fields in the die volume and in the sintered material in the SPS process are difficult to implement or simulate because they depend on many factors. The minimization of temperature gradients in the sample is possible only in the long-term (quasi-stationary) SPS mode that often leads to the growth of ceramic grains. In such a situation, the optimization of the SPS modes can only be carried out for specific products and dies. In this case, the transition to other sizes and dies may require re-optimization.

Nevertheless, the optimization and correct quantitative comparison of the results using different pressing schemes in SPS with the same modes is possible with a good coincidence of the volume and geometric die dimensions. The possible deviations of the real temperature of the sample from the values recorded on the surface die will be close for the collector and conventional dies having the same volume and parts geometry. This makes it possible to carry out a quantitative comparison of the sealing surfaces and the coefficients of the corresponding pressing equations to optimize the modes in these specific conditions of consolidation. It also allows applying the proposed approach to comparative optimization on other plants and materials.

It should be noted that for the same reason (closeness of the dimensions and geometry of the tooling), the use of a manifold pressing scheme and molds does not impose additional restrictions on the productivity and cost of implementing the SPS process. The use of a collector pressing scheme in SPS opens up prospects for the fabrication of products with complex shapes [11]. It favorably distinguishes this approach from compaction schemes of other widely used hot pressing options [20]. Moreover, the collector pressing scheme allows one to solve the well-known problem of limiting the prepressing pressure in the SPS process [16]. The conventional punches of SPS dies can transfer pressure to the sintered sample. The pressure is limited by the compression strength of the graphite. The loadbearing section of the pressing element can be larger than the section of the sample to be pressed using a collector pressing scheme. It makes it possible to apply a proportionally greater prepressing pressure to it in a die made of the same material.

The reasons for the anomalous increase in the transparency of thicker specimens made in SPS according to the uniaxial pressing scheme noted in the experiments are not yet clear. This issue requires separate experimental studies on YSZ and other ceramics, schemes for their consolidation under the SPS process, and atmospheric annealing modes. 


\section{Conclusions}

The efficiency of using the collector pressing scheme in the SPS process has been confirmed to improve the optical, physical, and mechanical properties of YSZ ceramics with an increased shape factor. A method for developing a seal surface and determining the optimal way of increasing pressure and temperature during SPS on this surface can be used to optimize the consolidation modes of the materials. The obtained results quantitatively confirmed that the most promising method for sintering transparent YSZ ceramics is to combine the SPS method with one of the rational methods of powder deformation, implemented according to the collector pressing scheme.

It has been shown that transparent/translucent YSZ ceramics with an increased shape factor $(14 \mathrm{~mm}$ in diameter and up to $5 \mathrm{~mm}$ in height, $\mathrm{h} / \mathrm{d}=0.36)$ can be successfully fabricated by the SPS technique combined with the collector pressing scheme. The optical properties and microhardness of ceramics obtained using the collector scheme is comparable or better to the optical properties of ceramics obtained using the conventional uniaxial pressing scheme. However, samples made in SPS according to the collector deformation scheme demonstrate a smaller CSR size and lattice microstresses, which can positively affect other operational properties of ceramics.

The reasons for the anomalous effect of the sample thickness on light absorption noted in our experiments, as well as a generalized assessment of the effect of the collector pressing scheme on the optical properties of transparent ceramics during SPS, is the subject of further studies.

Author Contributions: Conceptualization, O.K., E.D. and V.P.; methodology, E.D. and O.K.; validation, O.K., E.D. and M.F.; formal analysis, E.D. and V.P.; investigation, T.A., V.P. and A.A.; resources, O.K. and V.M.; data curation, S.S. and D.V.; writing-original draft preparation, V.P.; writing-review and editing, O.K., E.D., S.S., D.V. and A.C.; visualization, S.S. and D.V.; project administration, O.K. and M.F.; All authors have read and agreed to the published version of the manuscript.

Funding: This research was supported by Tomsk Polytechnic University Competitiveness Enhancement Program grant Number VIU-ISNPT-204/2020.

Institutional Review Board Statement: Not applicable.

Informed Consent Statement: Not applicable.

Data Availability Statement: The data presented in this study are available on request from the corresponding author.

Acknowledgments: The study was performed by "Innovation Centre for Nanomaterials and Nanotechnologies" of the National Research Tomsk Polytechnic University.

Conflicts of Interest: The authors declare no conflict of interest.

\section{References}

1. Prakasam, M.; Balima, F.; Cygan, S.; Klimczyk, P.; Jaworska, L.; Largeteau, A. Ultrahigh pressure SPS (HP-SPS) as new syntheses and exploration tool in materials science. In Spark Plasma Sintering; Elsevier: Amsterdam, The Netherlands, 2019 ; pp. $201-218$.

2. Hallam, D.; Heaton, A.; James, B.; Smith, P.; Yeomans, J. The correlation of indentation behaviour with ballistic performance for spark plasma sintered armour ceramics. J. Eur. Ceram. Soc. 2015, 35, 2243-2252. [CrossRef]

3. Paris, V.; Frage, N.; Dariel, M.P.; Zaretsky, E. The spall strength of silicon carbide and boron carbide ceramics processed by Spark Plasma Sintering. Int. J. Impact Eng. 2010, 37, 1092-1099. [CrossRef]

4. Balima, F.; Bellin, F.; Michau, D.; Viraphong, O.; Poulon-Quintin, A.; Chung, U.C.; Dourfaye, A.; Largeteau, A. High pressure pulsed electric current activated equipment (HP-SPS) for material processing. Mater. Des. 2018, 139, 541-548. [CrossRef]

5. Guillon, O.; Gonzalez-Julian, J.; Dargatz, B.; Kessel, T.; Schierning, G.; Räthel, J.; Herrmann, M. Field-assisted sintering technology/Spark Plasma Sintering: Mechanisms, materials, and technology developments. Adv. Eng. Mater. 2014, 16, 830-849. [CrossRef]

6. Anselmi-Tamburini, U.; Munir, Z.A.; Garay, J.E. Preparation of dense nanostructured functional oxide materials with fine crystallite size by field activation sintering. U.S. Patent No. 7,601,403, 13 October 2009.

7. Anselmi-Tamburini, U.; Garay, J.E.; Munir, Z.A. Fast low-temperature consolidation of bulk nanometric ceramic materials. Scr. Mater. 2006, 54, 823-828. [CrossRef] 
8. Faria, R.T., Jr.; Rodrigues, M.F.; de Andrade Esquef, I.; Vargas, H.; Filgueira, M. On the thermal characterization of a HPHT sintered WC-15\% wt Co hardmetal alloy. Int. J. Refract. Met. Hard Mater. 2005, 23, 115-118. [CrossRef]

9. Knaislová, A.; Novák, P.; Cygan, S.; Jaworska, L.; Cabibbo, M. High-pressure Spark Plasma Sintering (HP SPS): A promising and reliable method for preparing Ti-Al-Si alloys. Materials 2017, 10, 465. [CrossRef] [PubMed]

10. Barinov, V.Y.; Rogachev, A.S.; Vadchenko, S.G.; Moskovskih, D.O.; Kolobov, Y.P. Spark Plasma Sintering of products of complex shape with using of quasistatic pressing. Int. J. Appl. Fundam. Res. 2016, 1, 312-315.

11. Dvilis, E.S.; Khasanov, O.L.; Sokolov, V.M.; Pokholkov, J.P. Method for compacting powder materials into articles and a mold for implementing the method. U.S. Patent No. 6,919,041, 19 July 2005. Russian Patent \#2225280 (10.03.2004); Europatent \#№1459823 (11.03.2009).

12. Dvilis, É.S.; Paigin, V.D.; Stepanov, S.A.; Khasanov, O.L.; Valiev, D.T.; Polisadova, E.F.; Vaganov, V.; Alishin, T.R.; Dudina, D.V. Effect of Spark Plasma Sintering Temperature on the Properties of Transparent YSZ Ceramics. Refract. Ind. Ceram. 2019, 60, 154-159. [CrossRef]

13. Dvilis, E.S.; Khasanov, O.L.; Gulbin, V.N.; Petyukevich, M.S.; Khasanov, A.O.; Olevsky, E.A. Spark Plasma Sintering of aluminummagnesium-matrix composites with boron carbide and tungsten nano-powder inclusions: Modeling and experimentation. JOM 2016, 68, 908-919. [CrossRef]

14. ASTM C-1327-15. Standard Test Method for Vickers Indentation Hardness of Advanced Ceramics. 2015. Available online: https:/ / www.astm.org/Standards/C1327.htm (accessed on 1 December 2020).

15. Toby, B.H. R factors in Rietveld analysis: How good is good enough? Powder Diffr. 2006, 21, 67-70. [CrossRef]

16. Wang, S.; Zhang, J.; Luo, D.; Gu, F.; Tang, D.; Dong, Z.; Tan, G.; Que, W.; Zhang, T.; Li, S.; et al. Transparent ceramics: Processing, materials and applications. Prog. Solid State Chem. 2013, 41, 20-54. [CrossRef]

17. Shahbazi, H.; Tataei, M.; Enayati, M.H.; Shafeiey, A.; Malekabadi, M.A. Structure-transmittance relationship in transparent ceramics. J. Alloy. Compd. 2019, 785, 260-285. [CrossRef]

18. Krell, A.; Klimke, J.; Hutzler, T. Transparent compact ceramics: Inherent physical issues. Opt. Mater. 2009, 31, 1144-1150. [CrossRef]

19. Anselmi-Tamburini, U.; Woolman, J.N.; Munir, Z.A. Transparent nanometric cubic and tetragonal zirconia obtained by highpressure pulsed electric current sintering. Adv. Funct. Mater. 2007, 17, 3267-3273. [CrossRef]

20. Eugene, A.O.; Dina, V.D. Field-Assisted Sintering: Science and Applications; Springer: Cham, Germany, 2019. 